\title{
A Comparison of the Relationship between Malaria Parasite Density and Some Haematological Parameters in Malaria Infected Male and Female Subjects
}

\author{
Eze, Evelyn M. \\ Department of Medical Laboratory Science, Rivers State University of Science and Technology, Port Harcourt, Nigeria
}

\begin{abstract}
This study compared the relationship between the parasite density and some hematological parameters in malaria infected male and female subjects in Port Harcourt, Nigeria. A total of 226 malaria positive subjects (136 males and 90 females), aged between 170 years were recruited. QBC haematological analysis, QBC malaria parasite specie identification and quantification and thin blood film for differential leucocyte count were used. The mean values of the haematological parameters in each quartile of parasite densities were determined. Regression analysis was employed to model the mathematical relationship between parasite density and haematological parameters. In malaria positive males and females, neutrophil count had a negative exponential and polynomial relationship respectively with the parasite density. The relationship between lymphocyte count, monocyte count and eosinophil count and parasite density was logarithmic in both sexes. The best fitting regression model for total white blood cell count, haemoglobin concentration, packed cell volume and mean cell haemoglobin concentration and parasite density in both sexes was a linear model. Platelet count and parasite density in both sexes had a power relationship. The findings have demonstrated that whereas some of the relationships were not sex dependent, some were sex dependent.
\end{abstract}

Keywords: Regression model, parasite density, malaria, haematological parameters

\section{Introduction}

Malaria infection is caused by invasion of red blood cells by protozoan parasites of the genus Plasmodium. The female anopheles mosquito is the carrier of the parasite and transmits it to man by next blood meal. The bite of mosquito that carries the plasmodium leads to the presence of the parasite in red blood cells, causing symptoms that typically include fever and headache, in severe cases progressing to coma and death. The four Plasmodium species that infect humans are $P$. falciparum, $P$. vivax $P$. ovale and $P$. malariae. Occasional infections with monkey malaria parasite, such as $P$. knowlesi, also occur (Roberts et al., 2002).

Malaria is widespread in tropical and subtropical regions because of the significant amounts of rainfall and consistent high temperatures and high humidity, along with stagnant waters which provide mosquitoes the environment needed for continuous breeding (Prothero and Mansell, 1999). Malaria infection is a major public health problem in tropical areas,and it is estimated that the disease is responsible for 1 to 3 milliondeaths and 300-500 million infections annually worldwide (Agrava, \& Dhruva, 2014). Malaria is holoendemic in Nigeria with Plasmodium falciparum as the dominant strain (Lesi \& Adenuga, 1996).

Malaria parasitemia has been reported to have effects on some haematological parameters in many parts of the world (Layla etal., 2002; Oseni etal., 2006; Eze etal., 2012a). The vast majorityof morbidity and mortality from malaria is caused by infectionwith $P$. falciparum, mostly among children underthe age of 5 years living in sub-Saharan Africa (Saha etal., 2014). The infection with $P$. falciparum,which causes the most severe infections and nearly all malaria-relateddeaths, has been well documented in areas of high endemicityin Africa (Day \&Marsh, 1991). Haematologic changes, which are the most common complications, play a major role in fatal complications. They include anaemia, cytoadherence of infected red cells, leukocytic changes followed by the induction of cytokines, thrombocytopenia and coagulopathy, particularly disseminated intravascular coagulation (Elliott \& Beeson, 2008).

Malaria parasite identification request is usually accompanied with full blood count for proper diagnosis, treatment and management of malaria infection. There are several methods employed in malaria parasite identification and quantification. Some of these methods include; serological techniques, molecular techniques using Polymerase Chain Reaction (PCR), Quantitative Buffy Coat (QBC) technique and microscopic method using peripheral blood thick and thin films. These techniques are all with some limitations particularly in a resource limited environment like rural Nigeria.

Several rapid diagnostic tests have been developed which detect malaria parasite antigens in lysed blood using monoclonal antibodies. However, there are currently no known rapid diagnostic tests which can differentiate $P$. vivax, $P$. ovale, or $P$. malariae. These tests are not quantitative and will not provide any information about the levels of parasitemia. Antigen persistence is also a problem. PCR testing and QBC method offer a rapid, sensitive, and less subjective methods to determine the presence and species of Plasmodium. Unfortunately, these malaria tests are expensive and not routinely used in Nigeria. 


\section{International Journal of Science and Research (IJSR) \\ ISSN (Online): 2319-7064 \\ Index Copernicus Value (2013): 6.14 | Impact Factor (2014): 5.611}

Microscopic method using peripheral blood thick and thin films is commonly used for malaria diagnosis in Nigeria. This is because it is most economical. It is also reliable, sensitive and specific but the reliability, sensitivity and specificity of this method depend on the efficiency of the microscopist. Unfortunately in many laboratories in Nigeria, particularly in the rural areas, this manpower is lacking.

On the contrary, a good number of laboratory scientists and technicians in Nigeria can easily assay haematological parameters. Many malaria cases particularly children less than 5 years come as medical emergency and as such little time is available to diagnose, treat and save their lives. To reduce malaria-related deaths in future particularly in rural Africa, strategies on quick diagnosis and treatment should be adopted.

This study compared the regression models developed by Eze et al., (2012b) between some haematological parameters and the parasite density of the malaria infected males in Port Harcourtwith that developed by Eze, (2015) between some haematological parameters and the parasite density of the malaria infected females also in Port Harcourt as a tool for rapid malaria diagnosis.

\section{Subjects and Methods}

\subsection{Study Area}

The study was carried out in Port Harcourt city located between latitudes $4^{\circ} 2^{\prime}$ North and $4^{\circ} 47^{\prime}$ North and longitudes $6^{\circ} 55^{\prime}$ East and $7^{\circ} 08^{\prime}$ East. Port Harcourtt has continued to record a high incidence of malaria infection despite the federal government efforts to roll back malaria in Nigeria. The reason is that Port Harcourt is a typical coastal zone located in the Niger Delta of Nigeria. High temperatures and humidity as well as marked wet and dry seasons characterize the climate. The mean annual rainfall is estimated at about $2,405 \mathrm{~mm}$ while the mean monthly temperature varies between $24^{\circ} \mathrm{C}$ and $32^{\circ} \mathrm{C}$ throughout the year (Gobo, 1988). The mean annual temperature for Port Harcourt is $26^{\circ} \mathrm{C}$ (Gobo, 1988). The mean annual temperature, relative humidity and rainfall of Port Harcourt favour the development of both the parasite as well as the vector.

\subsection{Study Population}

The laboratory study was carried out for one year during which a total of two hundred and twenty six (226) malaria patients comprising of 136 males and 90 females were recruited. The inclusion criteria were out-patients to the participating clinic site within the ages of 1- 70 years queried for malaria infection with the presentation of at least one of the following: an oral temperature of $38^{\circ} \mathrm{C}$, headache, or a history of fever within the past 72 hours and who must not have commenced any treatments for malaria. Exclusion criteria were out-patients with pathological conditions outside malaria such as protozoan or helminthes infection, typhoid fever and HIV/AIDS, congenital manifestations such as sickle cell disease, physiological manifestations such as pregnancy and history of allergy. All enrolled patients were interviewed for information on current symptoms and previous malaria episodes and treatments.

\subsection{Blood Sample Collection and Processing}

A volume of $2.6 \mathrm{ml}$ of venous blood sample was drawn from each patient into monovette tubes containing the anticoagulant potasium ethylenediamine-tetra acetic acid (EDTA) for QB Chaematological analysis, QBC malaria parasite specie identification and quantification and thin blood film for differential leucocytes count. QBC Autoread Plus provided a diagnostic haematology profile of the following quantitative values from a single tube of blood: packed cell volume (haematocrit), haemoglobin concentration, mean corpuscular haemoglobin concentration, platelet count, white blood cell count, granulocyte count (percentage and number) and lymphocyte-monocyte count (percentage and number). Daily quality assurance checks were performed and recorded.

For QBC malaria parasite detection analysis, the centrifuged tube was examined under a fluorescence microscope in the region between the light red blood cells and granulocytes and lymphocytes/monocytes, where the parasites are most abundant. Examination of the centrifuged blood under a fluorescence microscope readily permits the detection of malaria parasite in the infected cells and plasma. Since the parasites contain DNA which takes up the acridine orange stain, they appear as bright specks of light in the dark background of non-fluorescing red cells.

For QBC malaria parasite species identification, at magnification of 600X, all parasites in the red blood cells were easily visualized and their morphologies identified. Species identifications were made based upon the size and shape of the various stages of the parasite and the presence of stippling and fimbriation. Plasmodium parasites are always intracellular, and they demonstrate, if stained correctly, blue cytoplasm with a red chromatin dot.

The parasite densities were obtained by multiplying the average number of parasites in 10 QBC fields by a factor of 10.5 (QBC operator's manual, 2006)

For a reliable differential leucocytes count, a thin blood film was prepared by a standard manual technique as described by Bain et al., (2008) on a clean grease-free glass slide, allowed to air-dry and fixed in methanol for 2 minutes and then stained with Field's stain. The differential leucocyte count was carried out by the longitudinal technique.

\section{Results}

The data obtained were grouped into four parasite densities (Table 1). Each group was subjected tostatistical analysis using Microsoft Excel statistical package. The relationships between the degree of parasitaemia and haematological parameters were determined using regression equation models. All regression relationships were tested and the relationship with the highest coefficient of determination $\left(\mathrm{R}^{2}\right)$ was accepted as the valid relationship. The relationships tested included linear, polynomial, exponential, logarithmic and power relationships. The $\mathrm{X}$ - axis of the regression graphs stand for the parasite density while Y-axis stands for the respective haematological parameters. 


\section{International Journal of Science and Research (IJSR) \\ ISSN (Online): 2319-7064 \\ Index Copernicus Value (2013): 6.14 | Impact Factor (2014): 5.611}

Heavy infection (3+) represented the highest percentage in both sexes accounting for $47.79 \%$ in the males, $42.22 \%$ in the female group. Scanty infection (1+) represented the least percentage in both sexes accounting for $13.97 \%$ in the male group and $12.22 \%$ in the female group (Table 1 ). The percentage of subjects manifesting very heavy infection (4+) was higher among the females (22.22\%) than the males (16.18\%).
Table 1: Distribution of the Male and Female Infected Subjects according to Levels of Parasitemia

\begin{tabular}{|l|c|c|}
\hline \multicolumn{1}{|c|}{ Level of Parasitaemia } & Male & Female \\
\hline scanty infection(+) & $19(13.97 \%)$ & $11(12.22 \%)$ \\
\hline moderate infection(2+) & $30(22.06 \%)$ & $21(23.33 \%)$ \\
\hline heavy infection $(3+)$ & $65(47.79 \%)$ & $38(42.22 \%)$ \\
\hline very heavy infection $(4+)$ & $22(16.18 \%)$ & $20(22.23)$ \\
\hline Total(N=226) & $\mathbf{1 3 6}(\mathbf{1 0 0} \%)$ & $\mathbf{9 0}(\mathbf{1 0 0} \%)$ \\
\hline
\end{tabular}

The variations of haematological parameters with changes in parasitemia in male and female infected subjects are shown in Tables $2 \mathrm{a}$ and $2 \mathrm{~b}$ respectively.

Table 2a: Mean \pm SD of Haematological Parameters of Males of Different Parasitemia

\begin{tabular}{|c|c|c|c|c|}
\hline Parameters & $1+$ & $2+$ & $3+$ & $4+$ \\
\hline $\mathrm{N}(\%)$ & $53.89 \pm 9.99$ & $58.37 \pm 5.03$ & $58.63 \pm 8.65$ & $61.41 \pm 4.17$ \\
\hline L (\%) & $34.95 \pm 9.58$ & $24.37 \pm 4.56$ & $22.11 \pm 6.69$ & $17.23 \pm 2.99$ \\
\hline M (\%) & $6.42 \pm 1.87$ & $8.70 \pm 2.61$ & $9.68 \pm 3.05$ & $10.59 \pm 2.13$ \\
\hline $\mathrm{E}(\%)$ & $5.26 \pm 1.59$ & $8.57 \pm 1.74$ & $9.49 \pm 1.91$ & $10.32 \pm 1.78$ \\
\hline B (\%) & $0.00 \pm 0.00$ & $0.00 \pm 0.00$ & $0.00 \pm 0.00$ & $0.00 \pm 0.00$ \\
\hline $\mathrm{WBC} / \mathrm{mm}^{3}$ & $6942.11 \pm 1868.55$ & $8026.67 \pm 1904.85$ & $9033.85 \pm 2340.76$ & $10231.82 \pm 3433.12$ \\
\hline $\mathrm{Hb}(\mathrm{g} / \mathrm{dl})$ & $13.67 \pm 1.35$ & $13.03 \pm 12.44$ & $12.44 \pm 1.54$ & $11.02 \pm 1.87$ \\
\hline PCV (\%) & $42.00 \pm 3.96$ & $40.77 \pm 39.09$ & $39.09 \pm 4.67$ & $35.15 \pm 4.98$ \\
\hline MCHC & $32.57 \pm 1.35$ & $31.93 \pm 1.91$ & $31.90 \pm 1.57$ & $31.26 \pm 1.86$ \\
\hline $\mathrm{Plt} / \mathrm{mm}^{3}$ & $\begin{array}{l}230526.32 \\
\pm 79240.40 \\
\end{array}$ & $\begin{array}{l}167733.33 \\
\pm 58997.33 \\
\end{array}$ & $\begin{array}{r}136198.46 \\
\pm 35752.55 \\
\end{array}$ & $\begin{array}{l}115545.45 \\
\pm 25688.11\end{array}$ \\
\hline Parasite Density P.falciparium(Parasite $/ \mu \mathrm{l})$ & $5.05 \pm 2.84$ & $50.07 \pm 25.53$ & $386.89 \pm 262.78$ & $1359.95 \pm 309.19$ \\
\hline
\end{tabular}

Table 2b: Mean \pm SD of Haematological Parameters of Females of Different Parasitemia

\begin{tabular}{|c|c|c|c|c|}
\hline Parameters & $1+$ & $2+$ & $3+$ & $4+$ \\
\hline N (\%) & $57.55 \pm 6.14$ & $59.38 \pm 4.41$ & $59.71 \pm 8.68$ & $60.75 \pm 4.93$ \\
\hline L (\%) & $28.73 \pm 6.68$ & $23.81 \pm 6.31$ & $21.66 \pm 7.97$ & $18.55 \pm 4.50$ \\
\hline M (\%) & $6.45 \pm 2.07$ & $9.57 \pm 2.75$ & $9.34 \pm 2.77$ & $10.50 \pm 1.99$ \\
\hline E (\%) & $6.18 \pm 1.25$ & $8.05 \pm 1.32$ & $9.11 \pm 1.93$ & $10.45 \pm 1.43$ \\
\hline B (\%) & $0.00 \pm 0.00$ & $0.00 \pm 0.00$ & $0.00 \pm 0.00$ & $0.00 \pm 0.00$ \\
\hline $\mathrm{WBC} / \mathrm{mm}^{3}$ & $7236.36 \pm 946.86$ & $7557.14 \pm 2042.69$ & $8981.58 \pm 2488.66$ & $10270.00 \pm 2680.75$ \\
\hline $\mathrm{HB}(\mathrm{g} / \mathrm{dl})$ & $12.65 \pm 0.61$ & $12.06 \pm 1.49$ & $11.63 \pm 1.37$ & $10.45 \pm 1.50$ \\
\hline PCV (\%) & $39.13 \pm 1.93$ & $37.10 \pm 4.02$ & $36.07 \pm 4.16$ & $33.07 \pm 4.12$ \\
\hline MCHC & $32.37 \pm 1.38$ & $32.50 \pm 1.76$ & $32.27 \pm 1.52$ & $31.49 \pm 1.07$ \\
\hline $\mathrm{PLT} / \mathrm{mm}^{3}$ & $272000.00 \pm 51828.56$ & $164952.38 \pm 41430.03$ & $132050.00 \pm 41129.84$ & $106150.00 \pm 21111.92$ \\
\hline PD (Parasite/ $\mu \mathrm{l})$ & $3.64 \pm 2.50$ & $46.52 \pm 20.36$ & $377.37 \pm 305.71$ & $1447.70 \pm 319.07$ \\
\hline
\end{tabular}

Figures 1-7 depicts the mathematical relationship between haematological parameters and parasite density in the male and female malaria infected subjects.

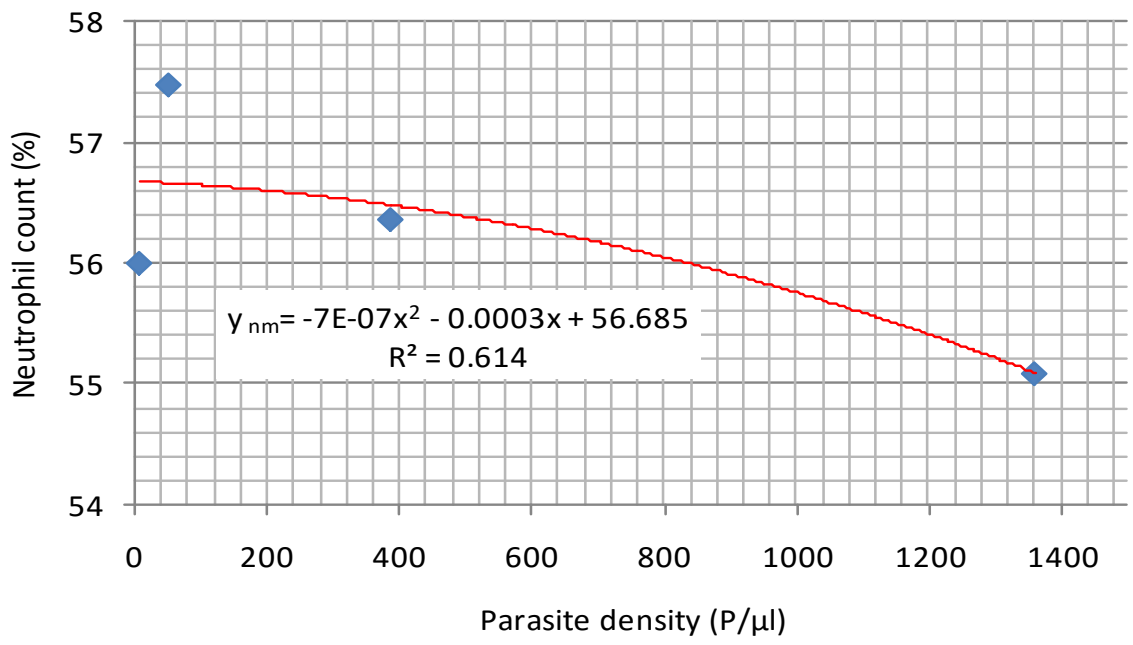

Figure 1a: Exponential Relationship between Neutrophil count and Parasite Density (Male) 
International Journal of Science and Research (IJSR)

ISSN (Online): 2319-7064

Index Copernicus Value (2013): 6.14 | Impact Factor (2014): 5.611

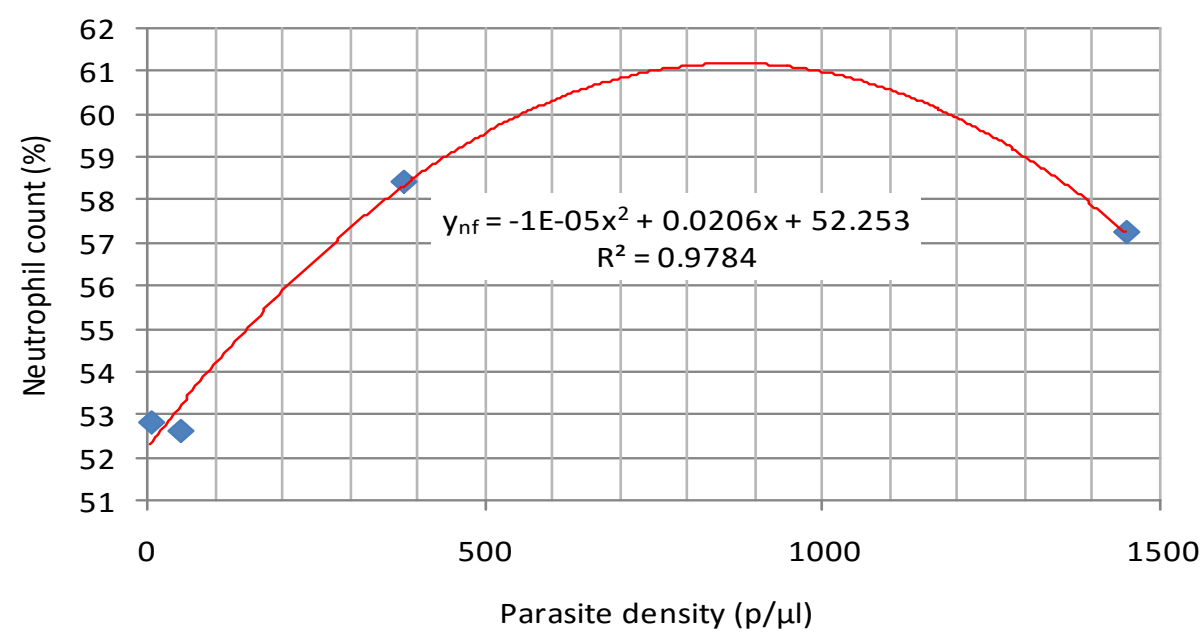

Figure 1b: Polynomial Relationship between Neutrophil count and Parasite Density (Female)

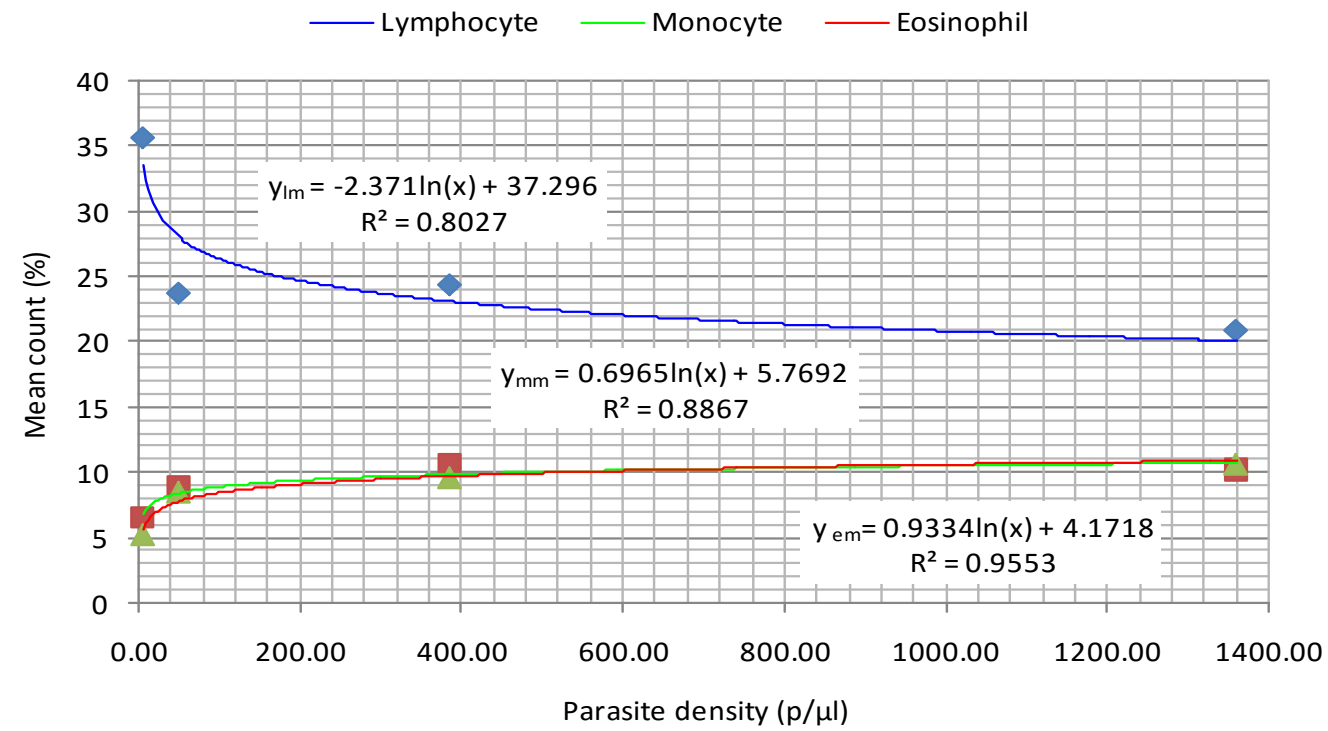

Figure 2a: Logarithmic Relationship between Lymphocyte, Monocyte and Eosinophil counts and Parasite Density (Male)

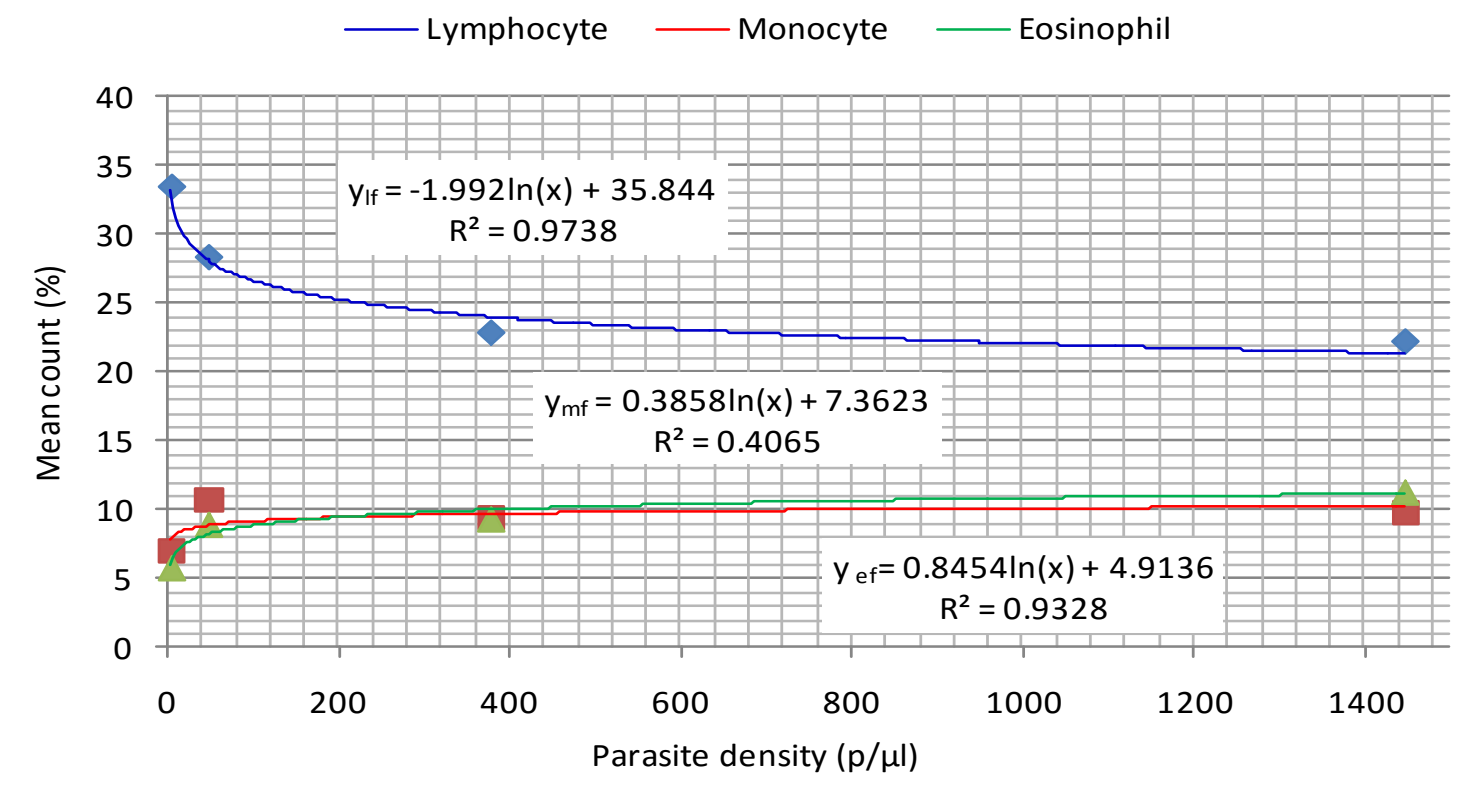

Figure 2b: Logarithmic Relationship between Lymphocyte, Monocyte and Eosinophil counts and Parasite Density (Female)

Volume 5 Issue 3, March 2016

www.ijsr.net 


\section{International Journal of Science and Research (IJSR) \\ ISSN (Online): 2319-7064}

Index Copernicus Value (2013): 6.14 | Impact Factor (2014): 5.611

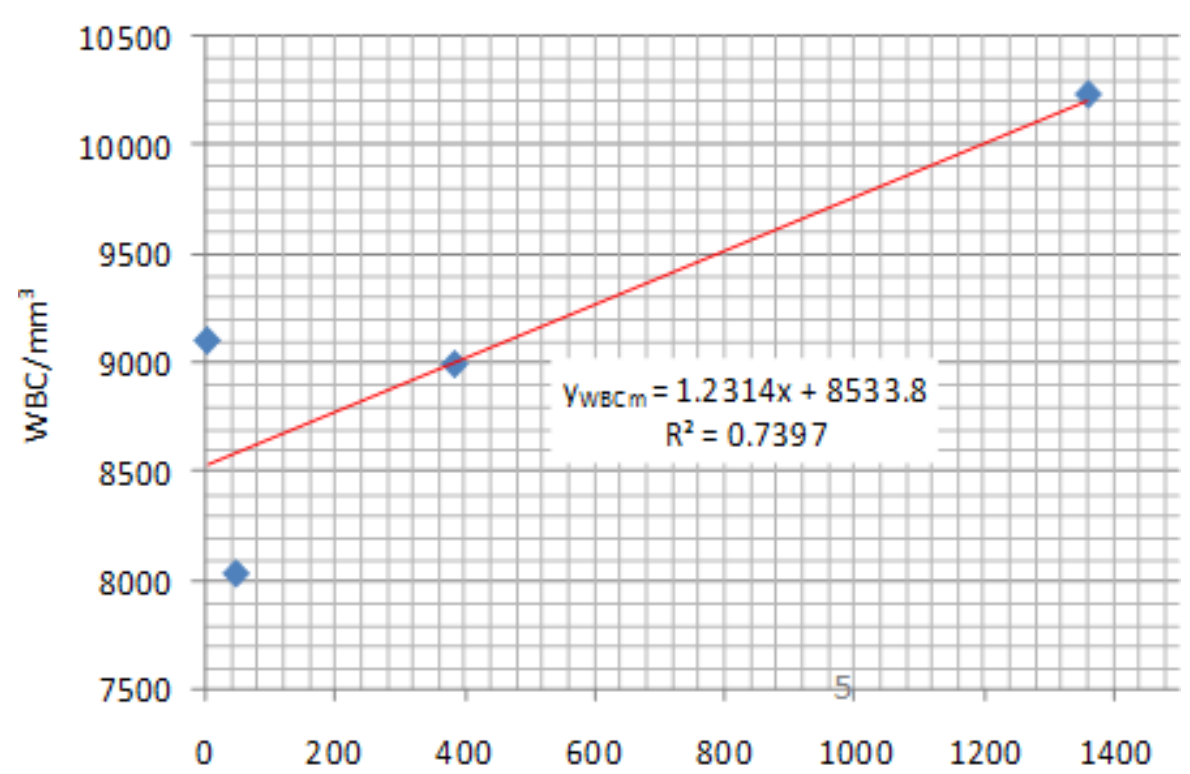

Figure 3a: Linear Relationship between WBC Count and Parasite Density (Male)

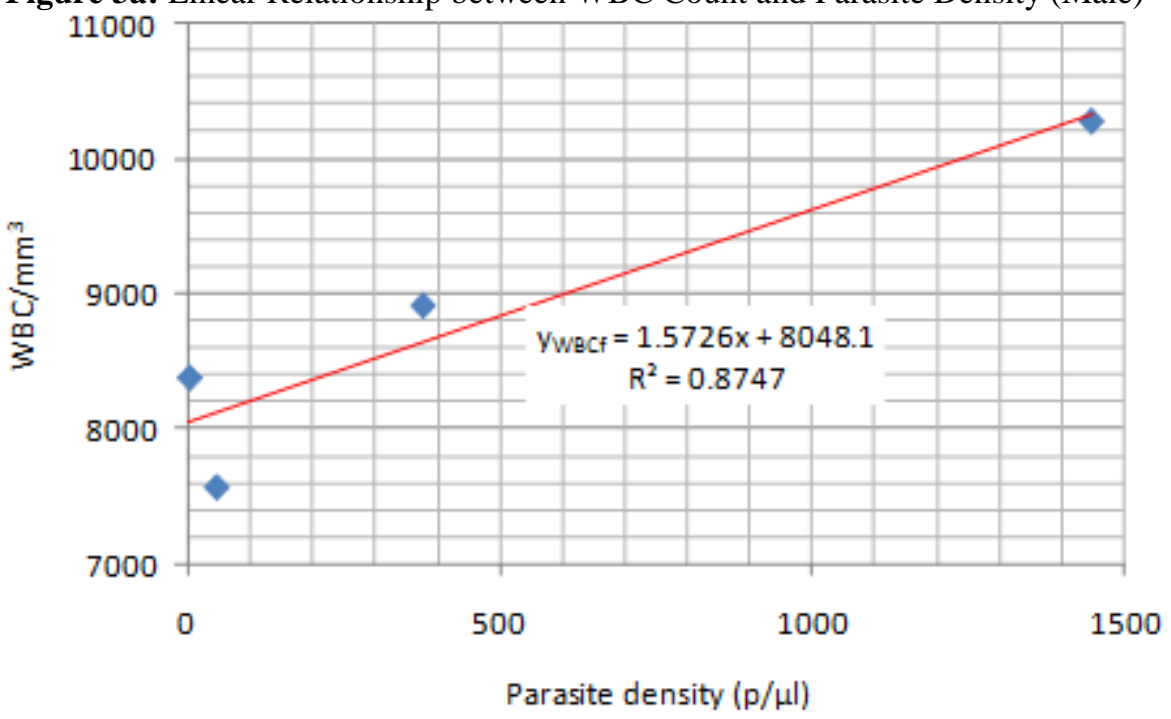

Figure 3b: Linear Relationship between WBC Count and Parasite Density (Female)

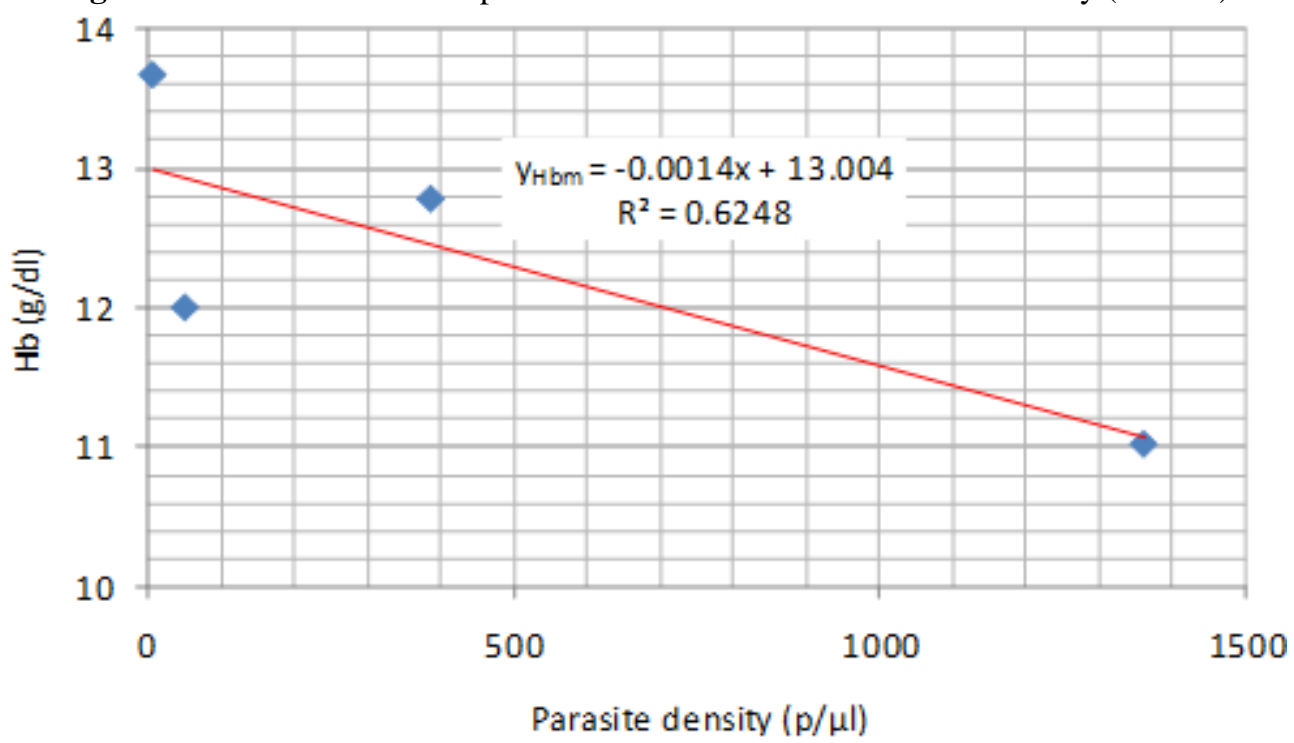

Figure 4a: Linear Relationship between Hb Concentraion and Parasite Density(Male)

Volume 5 Issue 3, March 2016 www.ijsr.net 


\section{International Journal of Science and Research (IJSR) \\ ISSN (Online): 2319-7064}

Index Copernicus Value (2013): 6.14 | Impact Factor (2014): 5.611

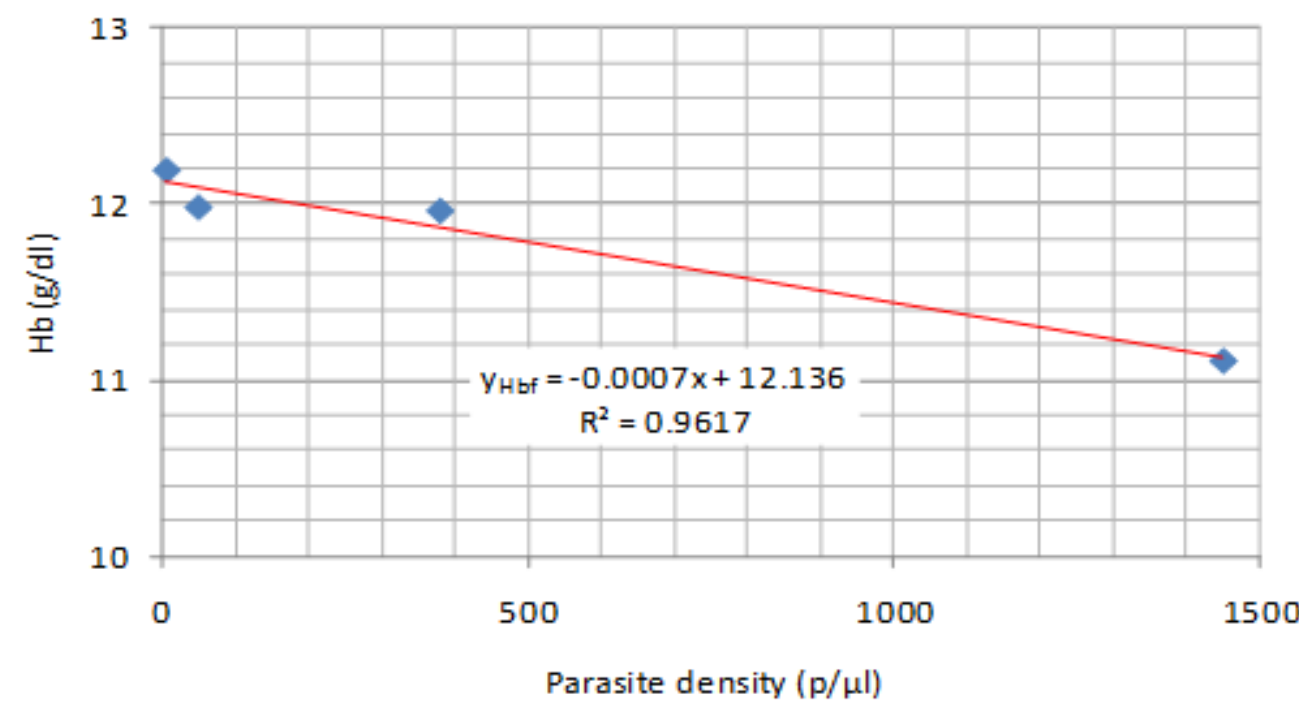

Figure 4b: Linear Relationship between Hb Concentraion and Parasite Density (Female)

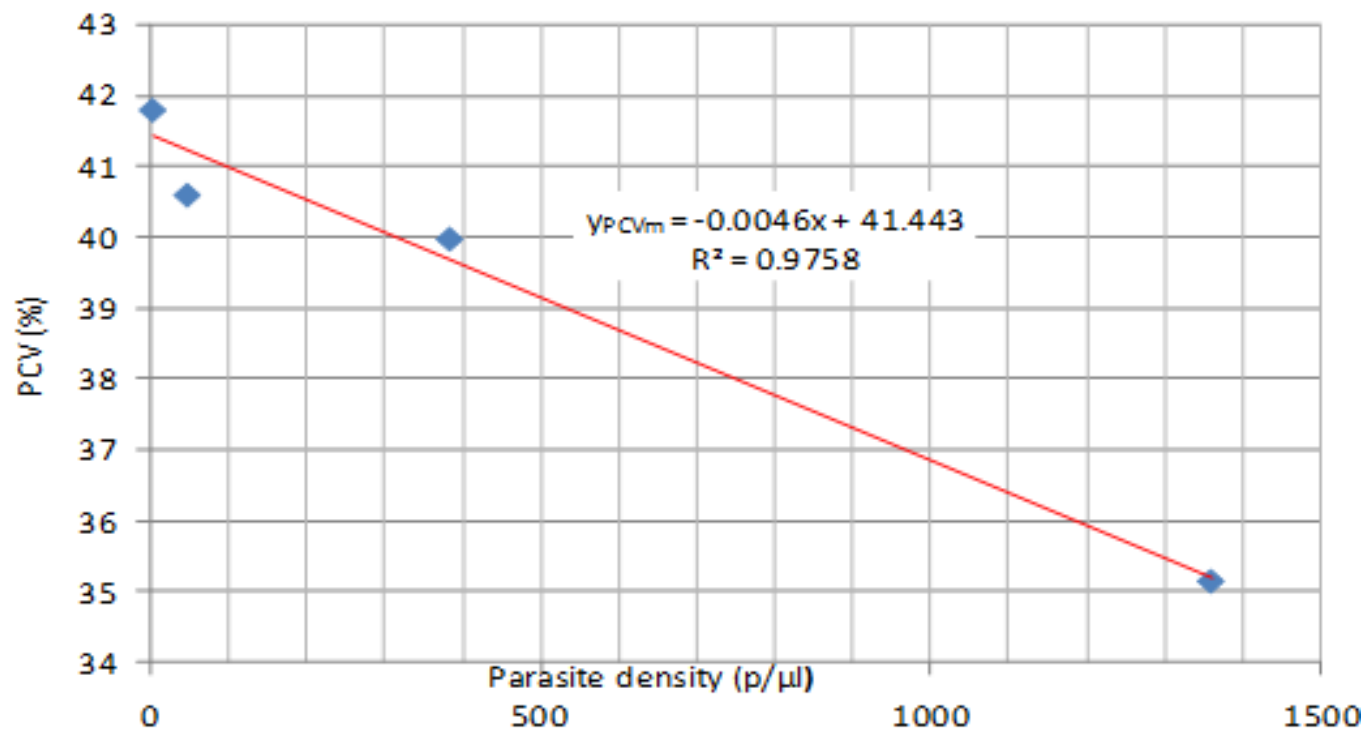

Figure 5a: Linear Relationship between PCV and Parasite Density (Male)

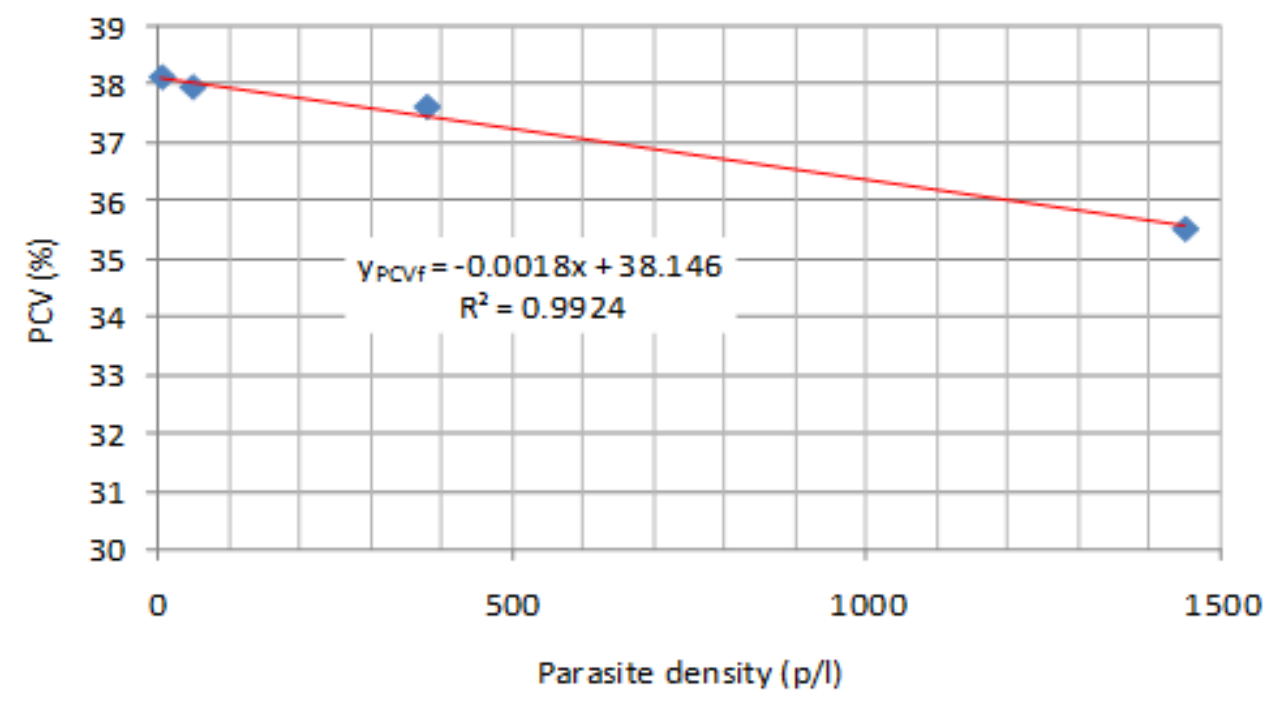

Figure 5b: Linear Relationship between PCV and Parasite Density (Female) 


\section{International Journal of Science and Research (IJSR) \\ ISSN (Online): 2319-7064}

Index Copernicus Value (2013): 6.14 | Impact Factor (2014): 5.611

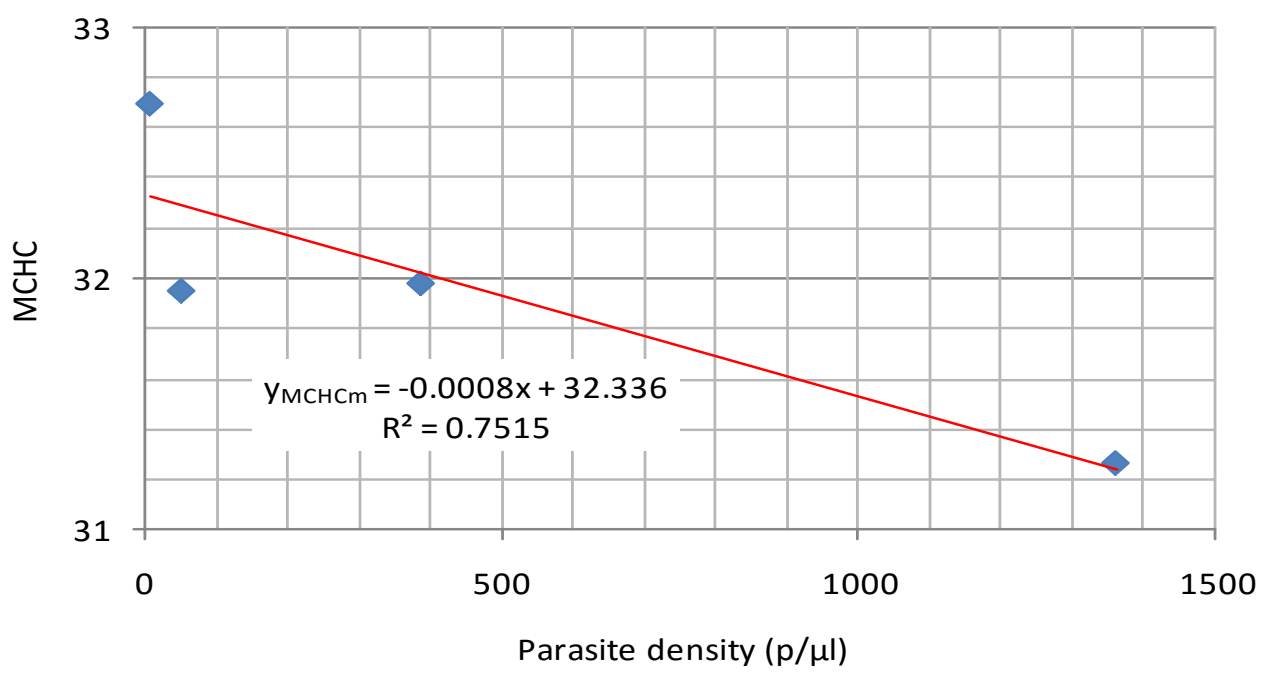

Figure 6b: Linear Relationship between MCHC and Parasite Density (Male)

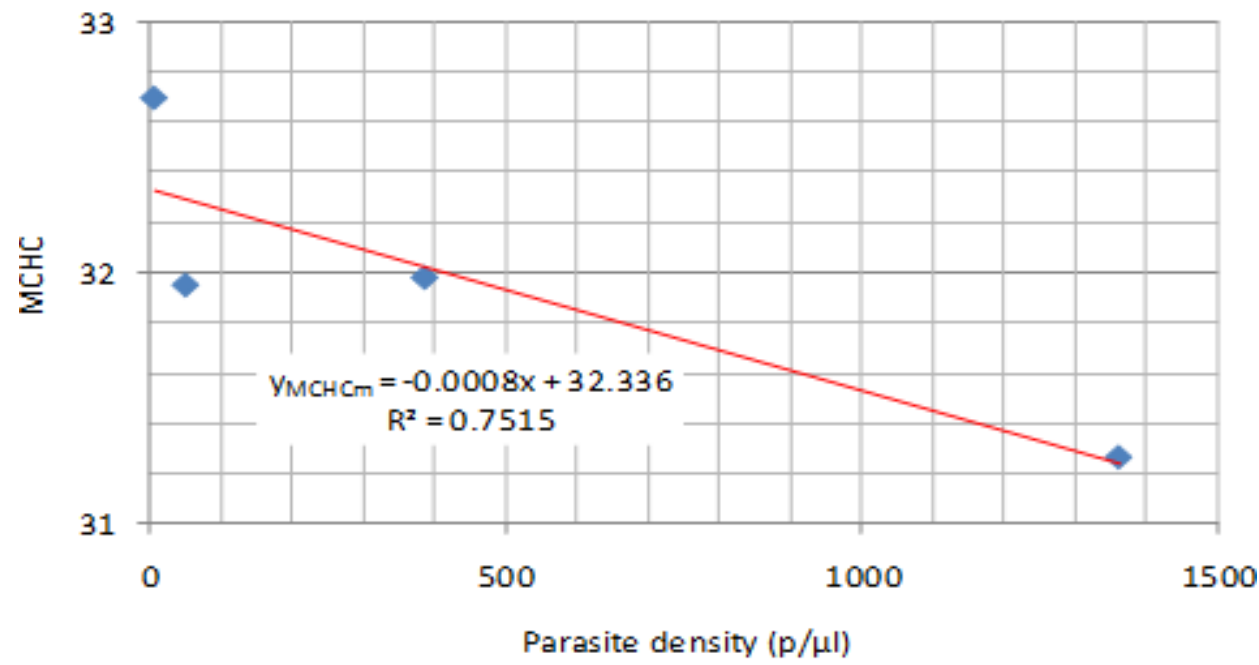

Figure 6b: Linear Relationship between MCHC and Parasite Density (Female)

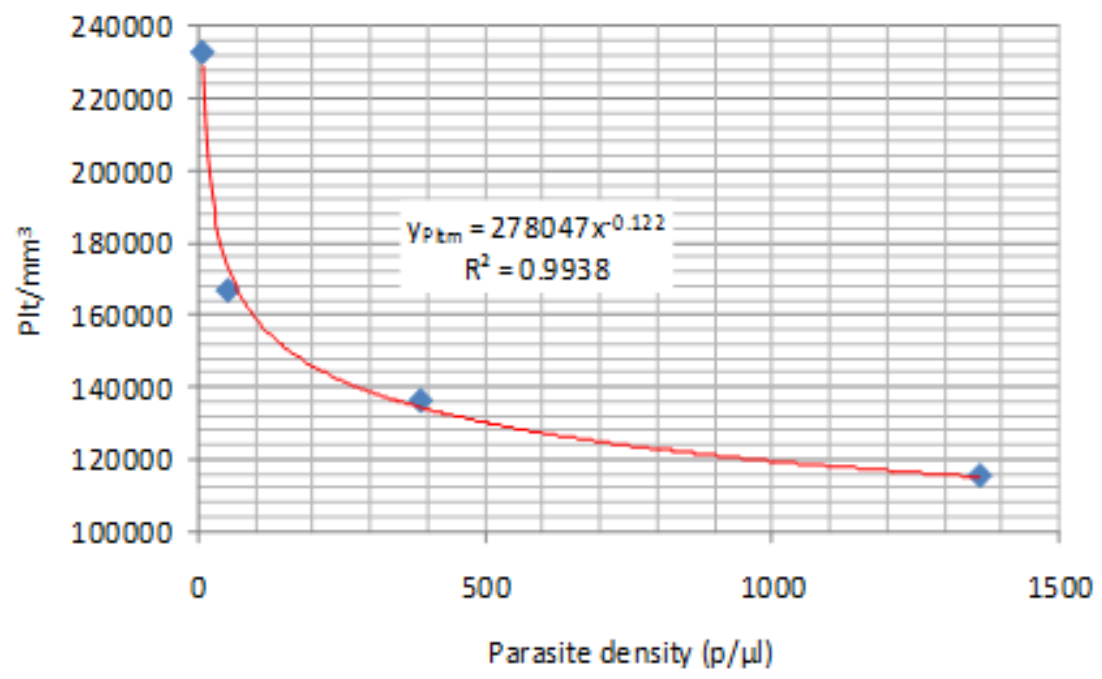

Figure 7a: Power Relationship between Plt Count and Parasite Density (Male) 


\section{International Journal of Science and Research (IJSR) ISSN (Online): 2319-7064}

Index Copernicus Value (2013): 6.14 | Impact Factor (2014): 5.611

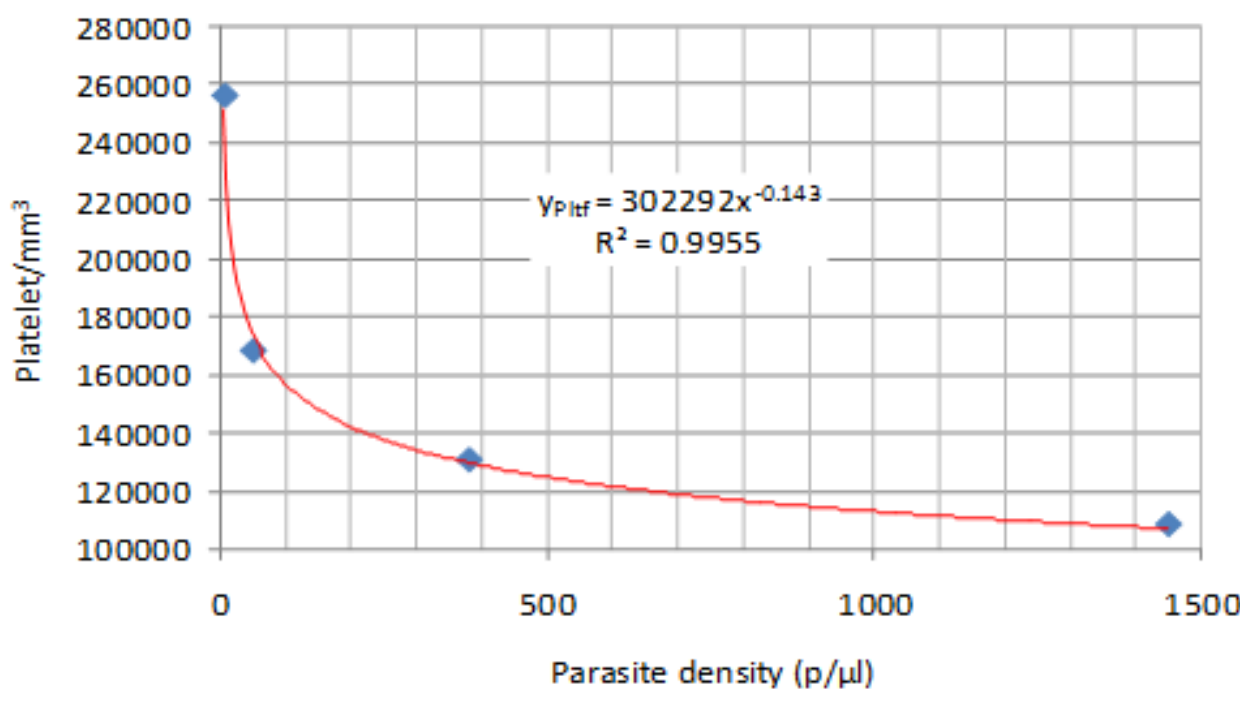

Figure 7b: Power Relationship between Plt Count and Parasite Density (Female)

\section{Discussions}

Neutrophil count in the males had negative exponential relationship with the parasite density while in the females; it had polynomial relationship with the parasite density. The negative exponential relationship between neutrophil count and parasite density in malaria infected males means that the rate of change of the parasitemia will depend on the initial value of the neutrophil but as the neutrophil increases, the parasitemia will tend to decrease in double, triple and quadruple manner.

Lymphocyte, monocyte and eosiniphil count had logarithmic relationships with parasite density in both sexes meaning that each doubling of lymphocyte, monocyte and eosiniphil count will cause the same amount of decrease in parasitemia. The implication of the logarithmic relationship is that each time the parasitaemia changed by a factor, the lymphocyte, monocyte and eosiniphil count changed by double that factor.

WBC had a positive linear relationship with parasite density in both sexes.This implies that as the parasite density is increases, there is a corresponding increase in total white cell count.

$\mathrm{Hb}$ conc, PCV and MCHC had a negative linear relationship with parasite density in both sexes. This means that as the parasite density is increases, there is a corresponding decrease in $\mathrm{Hb}$ conc, PCV and MCHC.

Platelet count in malaria infected male and female subjects exhibited a power relationship with parasite density. The value of the power relationship was less than $1(0.112)$ for males implying that a unit increment in platelet count will lower the parasite density by about a square of 0.112 .In case of malaria infected female subjects the value of the power relationship was also less than $1(0.143)$, implying that a unit increment in the parasite density will lower the platelet count by about a square of 0.143

\section{Conclusion}

The relationships between the parasite density in malaria patients and haematological parameters have been developed for both males and females. Whereas the relationships are the same for both sexes in some haematological parameters, the relationships for some are sex dependent.

\section{References}

[1] Agrava, A. H. \& Dhruva, G. A. (2010). Hematological Changes in Patients with Malaria. Journal of Cell and Tissue Research;10(3): 2325-2329.

[2] Bain, B.J., Lewis, S.M and Bates, I. (2008). Basic haematological techniques. In: Lewis, S.M., Bain, B.J and Bates, I. (Eds). Dacie and Lewis Practical Haematology; $10^{\text {th }}$ edition. Churchill Living Stone, Philadelphia. 25-57

[3] Day, K. P., \& Marsh, K. (1991). Naturally acquired immunity to Plasmodium falciparum.Immunology Today,12:68-71.

[4] Elliott, S.R \& Beeson, J.G. (2008). Estimating the burden of global mortality in children aged $<5$ years by pathogen-specific causes. Clinical Infectious Diseases; 46(11):1794-1795.

[5] Eze, Evelyn M., Uko, E. K., Ukaji, D. C., Ezeriuaku F. C., Nnatuanya, I. N. and Aroh K. N. (2012a). Haematological indices of Plasmodium falciparuim Malaria in Immune Adult Population of Port Harcourt, Nigeria. Advances in Science and Technology; 6:71-79

[6] Eze, Evelyn. M., Ezeiruaku, F.C \&Ukaji, D.C. (2012b). Experiential Relationship between Malaria Parasite Density and Some Haematological Parameters in Malaria Infected Male subjects in Port Harcourt, Nigeria. Global Journal of Health Science; 4(4):139148.

[7] Eze, Evelyn M. (2015). Experiential Relationship between Malaria Parasite Density and Some Haematological Parameters in Malaria Infected female subjects in Port Harcourt, Nigeria. Journal of Natural Sciences Research; 5(16):58-66

[8] Gobo, A. E. (1988). Relationship between rainfall trends and flooding in the Niger-Benue River Basins. Journal of Metereology; 13:220-224.

\section{Volume 5 Issue 3, March 2016}


[9] Layla, A. M., Bashawri, F.C. P.,Ahmed, A,. Mandil, P. H., Ahmed, A. B., Mirghan, A. \&Ahmed, M. D. (2002). Malaria: Hematological Aspects. Annals of Saudi Medicine; 22:372-376

[10] Lesi, F.E.A. \& Adenuga, A. O. (1996). Malaria in Childhood. An overview. NigeriaJournal of General Practice;1:9-12.

[11] Oseni, B. S. A., Togun, V.A., Olowu, A.O. \& Okoli, D.I. (2006). Impact of Severe Plasmodium falciparum Malaria on Red Cell Indices in Children below 10 Years of Age in Lagos, Nigeria. World Applied Science Journal;1: 4-7.

[12] Prothero, R. \& Mansell, A. (1999). Malaria, Forests and people in Southeeast Asia. Singapore Journal of Tropical Geography, 20(1): 76-85.

[13] Pounniotis, D. S., Poudfoot, O., Minigo, G., Hanley, J. L. \& Plebanski, M. (2004). Malaria parasite interaction with the human host. Journal of Postgraduate Medicine; 50:30-34.

[14] Price, R.N., Simpson, J.A., Nosten, F., Luxemburger, C., Hkirjaroen, L., Kuile, F., Chongsuphajaisiddhi, T. \& White, N.J. (2001). Factors contributing to anemia after uncomplicated falciparum malaria. American Journal of Tropical Medicine and Hygiene;65:614-622.

[15]QBC operator's/service manual (2006). QBC Diagnostic Incorporated, USA, 26pp.

[16] Roberts, D. R., Manguin, S., Rejmankova, E., Andre, R.., Harbach, R. E., Vanzie, E., Hakre, S., and Polanco, J. (2002): Spatial distribution of adult Anopheles darlingi and Anopheles albimanus in relation to riparian habitats in Belize, Central America. Journal of Vector Ecology, 27:21-30.

[17] Roshanravan, B., Kari, E., Gilman, R. H., Cabrera, L., Lee, E., Metcalfe, J., Calderon, M., Lescano, A. G., Montenegro, S. H., Calampa, C., \& Vinetz, J. M. (2003). Endemic malaria in the Peruvian Amazon region of Iquitos. American Journal of Tropical Medicine and Hygiene; 69:45-52.

[18] Saha, A. K., Maitra2, S. \& Hazra, S. C. (2014). Comparison of haematological parameters between Plasmodium falciparum, Plasmodium vivax and control group. International Journal of Medical Research\& Health Sciences, 3 (1): 120-127. 